\title{
Focused-ion-beam fabricated vertical fiber couplers on silicon-on-insulator waveguides
}

\author{
Jonathan Schrauwen, ${ }^{\text {a) }}$ Dries Van Thourhout, and Roel Baets \\ Photonics Research Group, Department of Information Technology, Ghent University-IMEC, 9000 Gent, \\ Belgium
}

(Received 26 April 2006; accepted 8 August 2006; published online 2 October 2006)

\begin{abstract}
Focused-ion-beam technology is a versatile micro- and nanostructuring tool, in which material is sputtered locally by a finely focused ion beam. But for photonic applications this process has the inherent inconvenience of generating optical losses due to ion induced damage. Process optimization is needed to reduce these losses. In this letter the authors present the focused-ion-beam fabrication of shallow gratings in silicon-on-insulator waveguides for the coupling of light to a vertically positioned fiber. Using $\mathrm{Al}_{2} \mathrm{O}_{3}$ as mask and $\mathrm{I}_{2}$ as selective etchant this resulted in a $24 \%$ fiber-to-chip coupling efficiency, which is comparable to similar devices fabricated with conventional etching techniques. () 2006 American Institute of Physics. [DOI: 10.1063/1.2356311]
\end{abstract}

Microfabrication with focused ion beam (FIB) consists of hitting a substrate locally with high energy ions; in most commercial systems these are gallium ions with energies around $30 \mathrm{keV}$. If the substrate is crystalline this process induces lattice damage, makes the top layer amorphous, and implants ions deeper into the substrate. ${ }^{1,2,15}$ These effects cause optical losses and make the direct fabrication of lowloss photonic devices nontrivial. FIB has been used to study various phenomena involving light in waveguides ${ }^{3,4}$ and allows the direct fabrication of structures such as photonic crystals. ${ }^{5,6}$ But there are few or no reports in literature about low-loss photonic devices fabricated in silicon-on-insulator by means of FIB.

The silicon-on-insulator (SOI) platform is a promising candidate for future ultra-compact photonic integrated circuits because of its compatibility with complementary metaloxide semiconductor (CMOS) technology. ${ }^{7}$ The high index contrast in this material system allows for the fabrication of short waveguide bends and thus circuits with a high degree of integration. The SOI wafers we use have a thin top silicon layer of $220 \mathrm{~nm}$ and a bottom oxide thickness of $1 \mu \mathrm{m}$. One of the difficulties of a high contrast platform is the coupling of light from optical fibers due to the large mode-size mismatch. This problem can be solved by using tapers or grating couplers. The latter are shallow gratings in broad waveguides that diffract light out of the waveguides into vertically positioned single-mode fibers. In previous work we have fabricated these shallow grating couplers with a CMOS compatible process (248 $\mathrm{nm}$ deep UV lithography and inductively coupled plasma etching) and optimized the parameters for optimal coupling efficiency $\left(25 \%\right.$ and more $\left.^{8}\right)$ and $1550 \mathrm{~nm}$ operation. ${ }^{9}$ However, it would be interesting to be able to make structures in situ, anywhere on a wafer. This would allow fast prototyping, trimming, and fault testing. FIB is the ideal tool for this. In this letter we present a method to make grating couplers with FIB, featuring a comparable efficiency but much larger flexibility than those of traditional fabrication methods. We compare different FIB etching schemes and optimize for lowest ion damage and best coupling efficiency. First grating couplers were etched directly into sili-

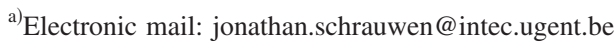

con waveguides using different acceleration voltages, with and without added gas. The efficiencies of these couplers are rather low, however. Therefore we have investigated different protective hard masks and chose $\mathrm{Al}_{2} \mathrm{O}_{3}$ as the best candidate. Waveguide loss measurements were performed to prove the protective ability of $\mathrm{Al}_{2} \mathrm{O}_{3}$. Finally we combined this hard mask with $\mathrm{I}_{2}$ as selective etchant and obtained a fiber-to-chip coupling efficiency of $24 \%$.

We use an FEI Nova 600 dualbeam that generates a $10 \mathrm{~nm}$ wide beam of $30 \mathrm{keV} \mathrm{Ga}{ }^{+}$ions. This beam is focused onto $10 \mu \mathrm{m}$ wide and $220 \mathrm{~nm}$ thick Si waveguides on SOI, with the purpose of etching a shallow grating pattern. The machine is equipped with a commercial gas injection system that can deliver $\mathrm{I}_{2}, \mathrm{H}_{2} \mathrm{O}$, and trifluoroacetamide (TFA) close to the beam spot through a fine needle. To determine the coupling efficiency we use a fiber-to-fiber transmission measurement for TE polarization. The structure consists of an input coupler, a $10 \mu \mathrm{m}$ wide waveguide, and an output coupler. We assume that both couplers are identical.

A first approach is to use FIB to directly etch the grating in $\mathrm{Si}$. We have tried this with 10 and $30 \mathrm{keV} \mathrm{Ga}{ }^{+}$ions, with and without $I_{2}$ as selective etchant. The results are presented in Fig. 1. Each curve in the graph is the most efficient from a set with different etch doses. The dose variation ranged from $4 \times 10^{17}$ to $40 \times 10^{17} \mathrm{Ga}^{+} / \mathrm{cm}^{2}$ in the case of direct etching and from $0.6 \times 10^{17}$ to $3.6 \times 10^{17} \mathrm{Ga}^{+} / \mathrm{cm}^{2}$ for the $\mathrm{I}_{2}$ etching process. The $30 \mathrm{keV}$ etches were performed with a beam current of $50 \mathrm{pA}$, the $10 \mathrm{keV}$ etches with a current of $120 \mathrm{pA}$ for the etching without gas, and $50 \mathrm{pA}$ for $\mathrm{I}_{2}$ etching. By making cross sections we verified that the expected optimal grating profile was covered in this dose range. We strived for the optimized gratings of previous work: 25 lines with a width of $315 \mathrm{~nm}$, a spacing of $315 \mathrm{~nm}$, and an etch depth of $70 \mathrm{~nm}$. But investigation of the cross sections showed that the structures are more "rounded" than the gratings fabricated with conventional techniques. This is caused by the Gaussian ${ }^{10}$ profile of the beam and redeposition. We performed finite-difference time-domain simulations with ellipselike grating slits rather than square ones and showed that there is little effect on the maximum obtainable efficiency if etch depth and filling factor are optimized. Figure 1 shows that the gratings fabricated without $I_{2}$ are very inefficient, 


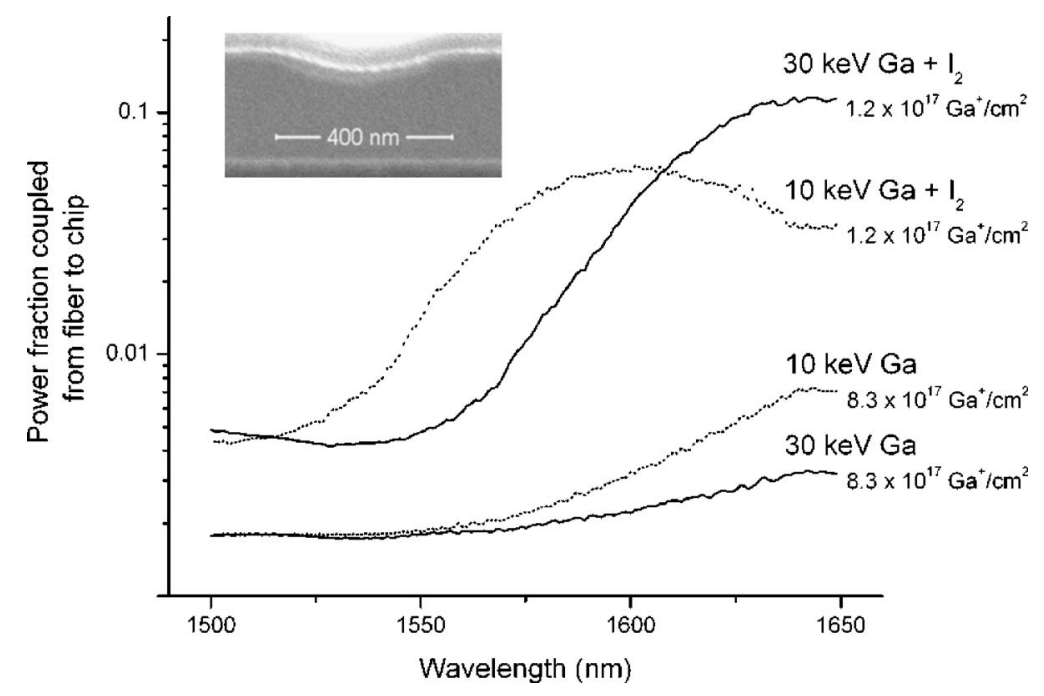

FIG. 1. Shallow grating couplers etched with FIB in SOI waveguides. By using $\mathrm{I}_{2}$ as etch enhancement gas the efficiency is greatly improved. The top left inset shows a FIB cross section through one grating slit etched with $\mathrm{I}_{2}$.

although they have cross sections that look more or less like the optimal ones. This very low efficiency of directly etched gratings was already noticed ${ }^{11}$ and is caused by the ion induced damage in the material. Figure 1 also shows that the gratings etched with $\mathrm{I}_{2}$ are much more efficient (about a factor of 20), although the cross section does not look less rounded (see inset of Fig. 1). This is explained as follows: $\mathrm{I}_{2}$ molecules (other halogens can also be used) are adsorbed on the $\mathrm{Si}$ surface and facilitate the extraction of $\mathrm{Si}$ atoms from the collision cascade by the formation of volatile species. ${ }^{12}$ So smaller doses are needed when $\mathrm{I}_{2}$ gas is used, and less ion damage is generated. Similar effects were seen on optically active material. ${ }^{13}$ Figure 1 shows a maximum fiber-to-chip coupling efficiency of about $11 \%$. This is still far below the efficiency of gratings made with classical etching techniques [about 25\% (Ref. 8)]. The reason for this are the nonoptimal dimensions of the gratings. The inconvenience of the enhanced etching process is the loss of dimensional control: one cannot etch $90^{\circ}$ sidewalls nor easily control the width of a hole. This is why we chose to work with a hard etch mask rather than to further optimize the direct etching with $\mathrm{I}_{2}$.

To choose the right material as etch mask we have calculated the sputter yields for several materials using the program SRIM (stopping and range of ions in matter ${ }^{14}$ ). Several metals have a lower sputter yield than $\mathrm{Si}(\mathrm{Cu}, \mathrm{Ni})$, but evaporated films of these materials have grains. Since the etch yield depends on crystal orientation, the etching of these grainy films is inhomogeneous. Therefore we chose $\mathrm{Al}_{2} \mathrm{O}_{3}$, an amorphous material, as etch mask. The difference in sputter yields of $\mathrm{Si}$ and $\mathrm{Al}_{2} \mathrm{O}_{3}$ can be enhanced by using $\mathrm{I}_{2}$ gas. A thin film of $\mathrm{Al}_{2} \mathrm{O}_{3}$ was evaporated on $\mathrm{Si}$ with an electron beam evaporation system. The purpose of this hard mask is twofold: it has to enhance dimensional control and it has to protect Si from ion damage in the regions where it does not need to be etched, e.g., during focalization of the beam. As can be calculated with the SRIM software the penetration depth of $30 \mathrm{keV} \mathrm{Ga}$ ions in $\mathrm{Al}_{2} \mathrm{O}_{3}$ is smaller than $30 \mathrm{~nm}$, so we chose a thickness of $50 \mathrm{~nm}$ for optimal protection. Figure 2 shows some experiments demonstrating the protective capacity of $\mathrm{Al}_{2} \mathrm{O}_{3}$. A section of $20 \mu \mathrm{m}$ on a multimode $10 \mu \mathrm{m}$ wide $\mathrm{Si}$ waveguide was etched with a perpendicularly incident focused ion beam. The doses were kept low enough to make the etched depth very small $(<10 \mathrm{~nm})$, so the transmission through these implanted waveguides is a measure for the optical losses generated by FIB etching. Figure 2 Downloaded 20 Oct 2006 to 157.193.172.109. Redistribution subje shows the losses for 10 and $30 \mathrm{keV}$ implanted waveguides, where the losses are presented in units of $\mathrm{dB} / \mu \mathrm{m}$. As expected the $30 \mathrm{keV}$ implantation produces more lossy waveguides, because the implantation depth is greater. The optical loss is of the order of $1 \mathrm{~dB} / \mu \mathrm{m}$, about four orders of magnitude bigger than that for nonimplanted waveguides. This explains why the directly etched gratings from Fig. 1 are so inefficient. For doses above $3 \times 10^{17} \mathrm{Ga}^{+} / \mathrm{cm}^{2}$ no transmission could be measured in our setup. We did the same experiment with waveguides that were covered with $50 \mathrm{~nm}$ of $\mathrm{Al}_{2} \mathrm{O}_{3}$. The inset in Fig. 2 shows the trajectory of $500 \mathrm{Ga}^{+}$ions that hit a $50 \mathrm{~nm}$ layer of $\mathrm{Al}_{2} \mathrm{O}_{3}$, after being accelerated to $30 \mathrm{keV}$. Not one of them can penetrate to the $\mathrm{Si}$, so as expected no significant dependence of the losses on the implantation dose was measured. This proves the protective capacity of the $\mathrm{Al}_{2} \mathrm{O}_{3}$ mask.

Finally we want to use this protective mask as a hard etch mask for making grating couplers in Si. FIB is used for the structuring of the hard mask in a first step. Afterwards one could use classic etching techniques, such as reactive ion etching, to etch the $\mathrm{Si}$, but for process simplicity and speed

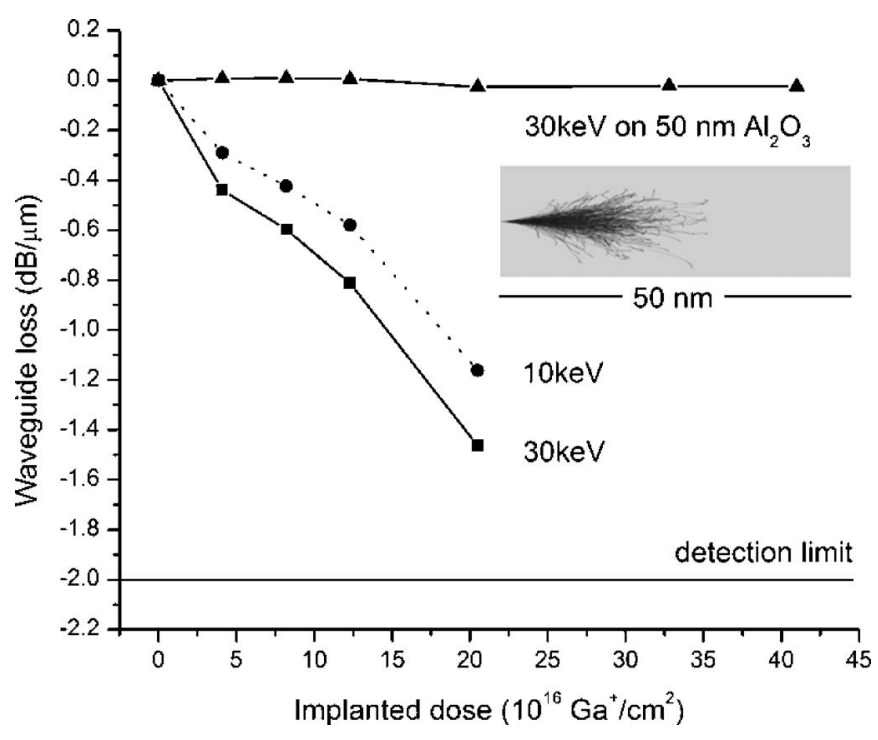

FIG. 2. Losses measured in waveguides that were etched with relatively small doses of $\mathrm{Ga}^{+}$ions. Higher energy implantation generates damage deeper into the layer and thus more loss. By adding $\mathrm{Al}_{2} \mathrm{O}_{3}$ as protective layer no significant losses were measured.

to AIP license or copyright, see http://apl.aip.org/apl/copyright.jsp 


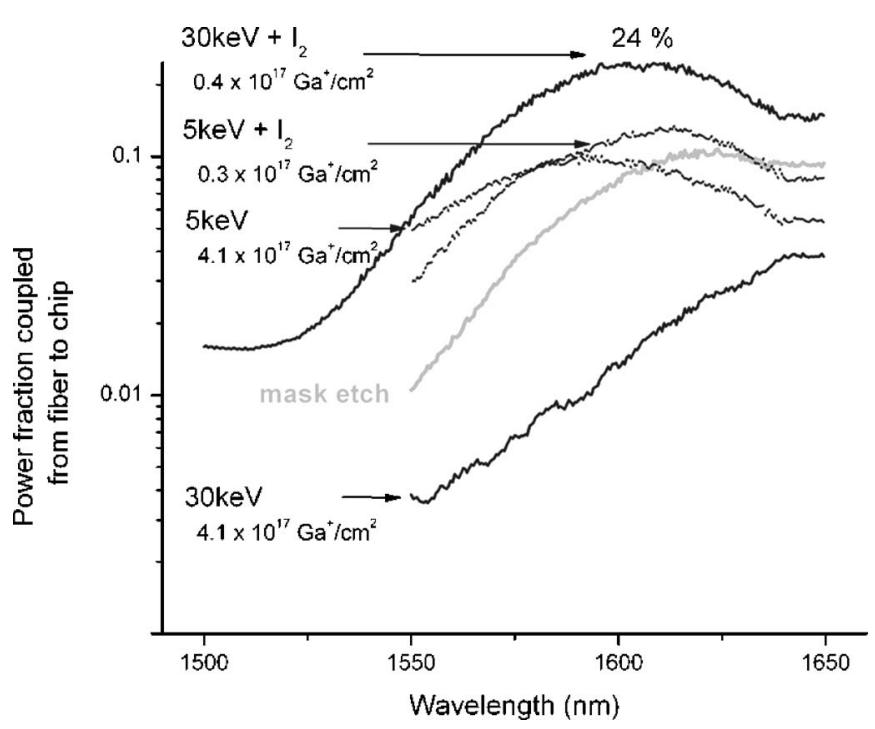

FIG. 3. Gratings fabricated with $\mathrm{Al}_{2} \mathrm{O}_{3}$ as mask using a two step etch process. The gray curve shows the coupling efficiency of a grating etched by only the first step. The second step was varied, and the most efficient gratings were produced with $30 \mathrm{keV}$ ions and $\mathrm{I}_{2}$ etch gas. The inset shows a cross section of a grating etched with mask and $\mathrm{I}_{2}$.

we chose to do the second step also with FIB. Figure 3 presents the measured coupling efficiencies for different etching schemes. The gray curve is a structure where only the first etch step is performed: the hard mask etch. We varied the dose and etch gas to optimize breakthrough. The best results were obtained by etching with TFA gas, dose of $12.3 \times 10^{17} \mathrm{Ga}^{+} / \mathrm{cm}^{2}$, beam energy of $30 \mathrm{keV}$, and beam current of $50 \mathrm{pA}$. A cross section after this etch step [Fig. 4(a)] shows that also the $\mathrm{Si}$ is etched, which explains the reasonable coupling efficiency of this grating. Figure 3 shows four different processes for the second etch step: 30 and $5 \mathrm{keV}$, with and without $\mathrm{I}_{2}$. This second etch step was performed by scanning a rectangle covering the entire grating. The $30 \mathrm{keV}$ etch without gas $\left(4.1 \times 10^{17} \mathrm{Ga}^{+} / \mathrm{cm}^{2}, 300 \mathrm{pA}\right)$ produced a very lossy coupler as expected, but by adding $\mathrm{I}_{2}$ to the process and doing some dose optimization we reached a coupling efficiency of $24 \%\left(0.4 \times 10^{17} \mathrm{Ga}^{+} / \mathrm{cm}^{2}, 50 \mathrm{pA}\right)$. This efficiency is comparable to those of couplers etched with traditional methods. The total etch time for one grating cou-
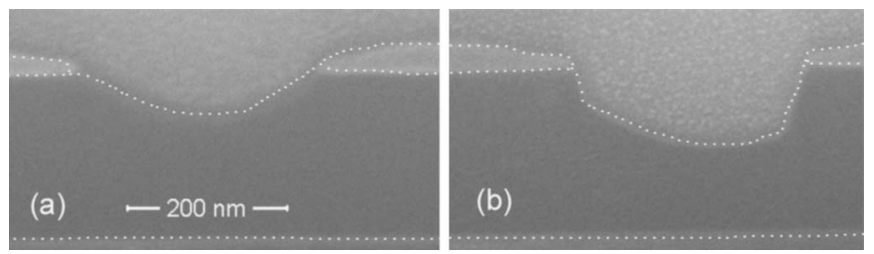

FIG. 4. Cross section through two slits of a grating etched (a) with TFA for mask break through and (b) followed by a second etch step with $\mathrm{I}_{2}$ gas and $30 \mathrm{keV}$ ions $\left(0.9 \times 10^{17} \mathrm{Ga}^{+} / \mathrm{cm}^{2}\right)$. The white dotted lines were added to increase the contrast. pler is about $5 \mathrm{~min}$. Because of the lower damage depth of the $5 \mathrm{keV}$ etch without gas $\left(4.1 \times 10^{17} \mathrm{Ga}^{+} / \mathrm{cm}^{2}, 70 \mathrm{pA}\right)$, the produced gratings were more efficient than the $30 \mathrm{keV}$ etch without gas, but we could not reach very high efficiencies by adding $\mathrm{I}_{2}$ to this process $\left(0.3 \times 10^{17} \mathrm{Ga}^{+} / \mathrm{cm}^{2}, 70 \mathrm{pA}\right)$. This might be caused by the lower chemical enhancement at lower acceleration voltages. Figure 4(b) shows a cross section of a grating that was etched with $30 \mathrm{keV}$ ions and $\mathrm{I}_{2}$, with a dose of $0.9 \times 10^{17} \mathrm{Ga}^{+} / \mathrm{cm}^{2}$. The asymmetry could not be removed by changing the scanning of the ion beam, so we think that it is caused by the directional gas injection of our system.

To conclude we have optimized the FIB etching of shallow grating couplers in silicon-on-insulator waveguides. Directly etched gratings are very lossy due to ion induced damage in the $\mathrm{Si}$, but by adding $\mathrm{I}_{2}$ as chemical enhancement and $\mathrm{Al}_{2} \mathrm{O}_{3}$ as mask we reached a coupling efficiency of $24 \%$, which is comparable to those of similar devices fabricated with classical etching techniques. This proves that FIB can be used for the fabrication of low-loss photonic devices.

This work was partly supported by the European Union through the Network of Excellence ePIXnet, by the Belgian IAP-PHOTON Network, and the Fund for Scientific Research. The authors would also like to thank F. Van Laere and D. Taillaert for useful discussions and help with the measurement setup.

${ }^{1}$ S. Rubanov and P. R. Munroe, J. Microsc. 214, 213 (2004).

${ }^{2}$ A. A. Tseng, J. Micromech. Microeng. 14, R15 (2004).

${ }^{3}$ C. Peeters, E. Fluck, A. M. Otter, M. L. M. Balistreri, J. P. Korterik, L. Kuipers, and N. F. Van Hulst, Appl. Phys. Lett. 77, 142 (2000).

${ }^{4}$ D. J. Moss, V. G. Ta'eed, B. J. Eggleton, D. Freeman, S. Madden, M. Samoc, B. Luther-Davies, S. Janz, and D. X. Xu, Appl. Phys. Lett. 85, 4860 (2004).

${ }^{5}$ S. Cabrini, A. Carpentiero, R. Kumar, L. Businaro, P. Candeloro, M. Prasciolu, A. Gosparini, C. Andreani, M. De Vittorio, T. Stomeo, and E. Di Fabrizio, Microelectron. Eng. 78-79, 11 (2005).

${ }^{6}$ L. Vogelaar, W. Nijdam, H. A. G. M. Van Wolferen, R. M. De Ridder, F. B. Segerink, E. Fluck, L. Kuipers, and N. F. Van Hulst, Adv. Mater. (Weinheim, Ger.) 13, 1551 (2001).

${ }^{7}$ W. Bogaerts, R. Baets, P. Dumon, V. Wiaux, S. Beckx, D. Taillaert, B. Luyssaert, J. Van Campenhout, P. Bienstman, and D. Van Thourhout, J. Lightwave Technol. 23, 401 (2005).

${ }^{8}$ P. Dumon, W. Bogaerts, D. Van Thourhout, D. Taillaert, R. Baets, J. Wouters, S. Beckx, and P. Jaenen, Opt. Express 14, 664 (2006).

${ }^{9}$ D. Taillaert, P. Bienstman, and R. Baets, Opt. Lett. 29, 2749 (2004).

${ }^{10}$ A. Lugstein, B. Basnar, G. Hobler, and E. Bertagnolli, J. Appl. Phys. 92, 4037 (2002).

${ }^{11}$ K. E. Zinoviev and C. Dominguez, Opt. Express 13, 8618 (2005).

${ }^{12}$ K. Edinger and T. Kraus, Microelectron. Eng. 57-58, 263 (2001).

${ }^{13}$ Y. Sugimoto, M. Taneya, H. Hidaka, and K. Akita, J. Appl. Phys. 68, 2392 (1990).

${ }^{14}$ J. F. Ziegler, Nucl. Instrum. Methods Phys. Res. B 219-220, 1027 (2004).

${ }^{15}$ J. Gierak, E. Bourhis, M. N. M. Combes, Y. Chriqui, I. Sagnes, D. Mailly, P. Hawkes, R. Jede, L. Bruchhaus, L. Bardotti, B. Prevel, A. Hannour, P. Melinon, A. Perez, J. Ferre, J. P. Jamet, A. Mougin, C. Chappert, and V. Mathet, Microelectron. Eng. 78-79, 266 (2005). 